
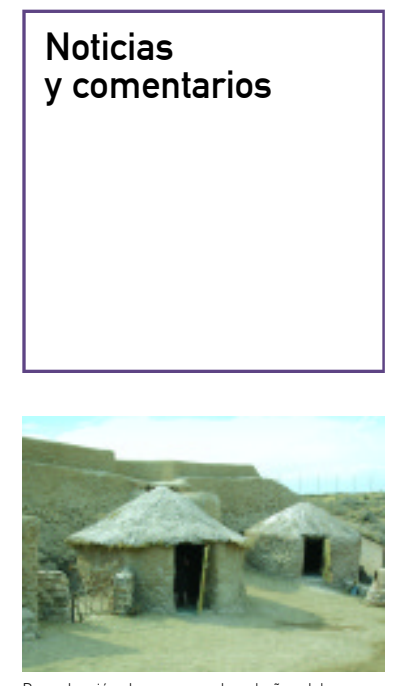

Reproducción de un grupo de cabañas del poblado de Los Millares

\footnotetext{
${ }^{1}$ Agradecemos a Fernando Molina González, director de este proyecto de investigación, su constante apoyo e indicaciones para el desarrollo de este Centro de Interpretación. Igualmente hay que agradecer al Servicio de Investigación y Difusión de la Dirección General de Bienes Culturales de la Consejería de Cultura de la Junta de Andalucia su apuesta por este proyecto y su financiación, apoyo canalizado a través de la Empresa Pública de Gestión de Programas Culturales. Por último, tenemos que señalar aquí la valiosa colaboración de los trabajadores de la Empresa Procasa de Almería y del personal del Yacimiento Arqueológico de Los Millares.

${ }^{2}$ La Consejería de Cultura de la Junta de Andalucía apuesta en un futuro próximo por la ampliación del Complejo Interpretativo con la reconstrucción de la cubierta vegetal mediante las especies documentadas en el yacimiento, y la incorporación de las condiciones hídricas habidas en la zona durante la Edad del Cobre.
}

\title{
El Centro de Interpretación de Los Millares recrea la vida de la prehistoria andaluza
}

El Proyecto de Investigación "Los inicios de la metalurgia en el sureste de la Península Ibérica"1, centrado en el yacimiento de Los Millares (Santa Fe de Mondújar, Almería), ha cumplido en 2005 sus veinte años de existencia entre campañas de campo, de laboratorio y de restauración, por lo que los resultados obtenidos son suficientes como para proponer un modelo urbanístico y arquitectónico que atienda tanto al entorno doméstico como al funerario sin descuidar el defensivo, que es el que realmente condiciona los espacios anteriores.

La construcción del Centro de Interpretación surge como una fase más de la investigación en el yacimiento, en la que se vuelve a montar ordenadamente los restos estructurales y materiales exhumados en un proceso inverso al previo de excavación y atendiendo a la estratigrafía como vínculo aglutinante entre ellos. De esta forma, el nuevo espacio proyectado surge tanto como una invitación al conocimiento de un momento fundamental de la prehistoria andaluza, como para nuestro propio enriquecimiento metodológico e investigador al poder experimentar el proceso constructivo de un poblado no vivido empleando además materiales tampoco antes utilizados.

\section{Propuestas iniciales}

La difusión del patrimonio arqueológico, en este caso concreto, se convierte en uno de los objetivos fundamentales de la investigación. Esta idea nos lleva en primer lugar a la elección del lugar en donde proyectar el centro. Este lugar debía cumplir al menos tres requisitos: el primero, la proximidad al Centro de Recepción y al propio yacimiento, para incluirlo en el circuito de visitas; en segundo lugar, su integración dentro de un paisaje y un medio ambiente propio, es decir, el que muestra el yacimiento, enfatizando su importancia como proveedor de materias primas, punto clave de un sistema de intercambios a más larga distancia, enclave cómodamente defendible, o su facilidad para la captación de recursos naturales (fauna, flora, cursos de agua regulares...); la tercera exigencia tiende a mimetizar la nueva construcción lo máximo posible tanto para evitar su competencia con el yacimiento arqueológico como para soslayar el impacto visual desde cualquier otro punto del entorno.

Con este enfoque se proyectó la construcción de la réplica arqueológica en un área más o menos equidistante a los otros dos puntos del recorrido, Centro de Recepción y yacimiento, cercano a la carretera comarcal que lleva a Santa Fe de Mondújar y al interior de la valla que delimita el Conjunto Arqueológico, en una zona de servidumbre estéril desde el punto de vista arqueológico. Por lo demás se trata de un espacio que reúne los condicionantes topográficos precisos para el desarrollo del proyecto a corto y largo plazo ${ }^{2}$.

\section{Recreación de los espacios}

Para la recreación del espacio se apostó por reproducir un área del yacimiento que incorporara espacios de talleres domésticos, funerarios y defensivos, que mostrara el nivel tecnológico alcanzado, y que fuese capaz de trasmitir los diferentes sistemas de producción, sus bases económicas, el ideario y la simbología del momento, etc.

La información contenida en los diferentes conjuntos estructurales procede del análisis y estudio del registro arqueológico recuperado, es decir proviene de restos materiales (artefactos y ecofactos) directos e indirectos, contextualizados y con una estratigrafía clara. A la hora de la construcción se han tenido en cuenta, entre otros, los volúmenes más apropiados para cada una de las estructuras, observando no sólo sus proporciones y su relación con el conjunto, sino que también, en este punto, nos hemos basado en el registro arqueológico al analizar el volumen de los diferentes derrumbes de piedra documentados.

Se ha reproducido una zona singular de la Línea I de muralla en su sector norte. Desde la entrada al recinto se identifica un tramo de muralla, que se va adaptando al terreno, de unos $14 \mathrm{~m}$ de longitud, que alterna dos torres y dos bastiones. Al exterior de esta línea se desarrolla una zona de necrópolis en la que se diferencian dos sepulturas, tipo tholoi, de las que una, la de mayor tamaño, se puede visitar. En el interior de la muralla se han recreado diversas estructuras que corresponden a áreas de viviendas, dos unidades exentas y visualmente conectadas a la muralla mediante tirantes de mampostería que, a su vez, crean un espacio que se aprovecha como corral.

En el interior de estas viviendas domésticas se recogen diversas tareas de la vida cotidiana: la primera de ellas presenta una zona textil con un telar vertical, que muestra una tela tejida en el propio telar; y en la segunda un área de fabricación de vajillas para usos diferentes (cocina, mesa...), en las que se observan las diversas 


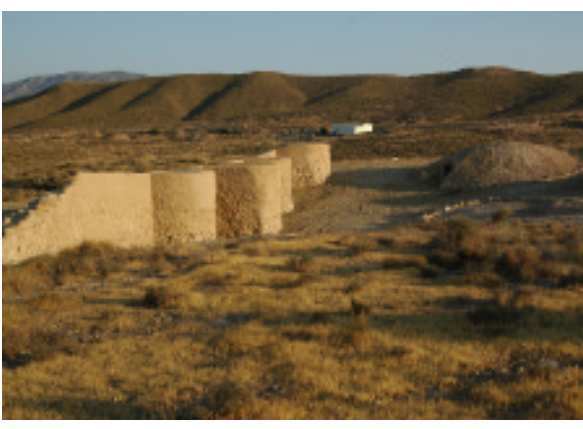

Vista general del Centro de Interpretación

maneras de modelarlas (mediante churros, sobre molde de esparto...) junto a otras formas cerámicas (queseras, soportes...).

Las actividades de producción se integran en diversos talleres (talla de útiles en silex, curtido de pieles, manufactura del esparto, molienda...) situados en el interior de las dos torres. Tanto en las viviendas como en el interior de estos últimos espacios se reserva una zona como lugar de descanso, delimitada por un jergón de esparto trenzado bajo una piel, de cabra normalmente. Igualmente se han reproducido, en cada uno de estos espacios, determinados elementos estructurales, como hogares, pequeños banquitos de mampostería adosados, etc., que ayudan a crear la ambientación necesaria.

De esta misma forma está representada una de las tareas más importantes como sostén económico de Los Millares como es la metalurgia, mediante la reproducción de un taller, adosado a la muralla, en cuyo interior se muestran los elementos implicados en cada una de las fases del proceso metalúrgico, transformación, reducción, fundición y acabado, en el que se reconocen tanto las piezas que se transformarán en útiles como aquellos otros que están dirigidos bien al comercio (tortas de metal), bien como stock de provisiones, junto a un repertorio significativo de cuantos útiles domésticos y armamentísticos se exhumaron en el yacimiento.

Continuando con el interior de la línea de muraIla y para ambientar mejor el conjunto se explicitan, mediante una serie de elementos, otras actividades y usos de espacios que serían comunes a un grupo de viviendas: un huerto cerrado mediante una empalizada asociado a aperos de labranza, un pequeño horno para la cocción de alimentos, leñeras situadas en zonas concretas del recorrido, pequeños bancos adosados al exterior de algunas de las estructuras ya comentadas, así como un espacio central entre cabañas en donde se realizarian algunas de estas tareas comunales como por ejemplo la molienda tal y como se recoge en el yacimiento.

La construcción de los espacios funerarios está pensada, al igual que el resto de construccio- nes, para que el visitante se haga una idea lo más exacta posible no sólo de las actividades que se desarrollaban en cada uno de los espacios mostrados sino también para que se impregnen de determinados aspectos que quedan fuera de lo estrictamente material y que tienen que ver, por tanto, con la simbología y los ideales de un poblado antaño desaparecido. Por este motivo y con estas intenciones se han creado espacios en los que la posición de determinados elementos, las luces y sombras que se proyectan, los enclaves elegidos o la misma dirección cardinal de la estructura, crean una atmósfera que envuelve, condiciona y transmite de alguna forma al visitante esos efectos tan dificiles a veces de materializar, y así, de alguna manera, les predisponen desde el inicio mismo de la visita.

Esta zona de necrópolis está representada, como antes se ha comentado, por dos sepulturas colectivas o tholoi, de los que una de ellas es objeto de visita pública. En concreto se trata de un enterramiento que presenta un amplio vestíbulo por el que se accede a un corredor de unos $5 \mathrm{~m}$ de longitud y en uno de cuyos laterales se abre un nicho. El extremo del corredor da paso a una gran cámara abovedada, con sistema de falsa cúpula, de forma circular. En el vestíbulo, en una de sus esquinas, junto a la zona de entrada al corredor, se acumula una gama diversa de betilos.

En el nicho del pasillo se colocó la recreación de un enterramiento infantil con varios objetos como ajuar funerario. En la cámara circular se disponen hasta seis esqueletos en posiciones diversas que inciden en el rito de enterramiento. Cada uno de ellos se acompaña de un ajuar con elementos característicos de los objetos recuperados en estos espacios.

En la construcción de las diferentes estructuras del Centro de Interpretación se han tenido en cuenta los análisis de los materiales empleados en el propio yacimiento. La totalidad de las réplicas que ambientan los diferentes espacios se han realizado de forma manual, siguiendo la tecnología de la época, empleando herramientas primitivas y productos naturales.

Auxilio Moreno Onorato

Martín Haro Navarro

GEPRAN (Grupo de Estudios de la

Prehistoria Reciente de Andalucia)

Universidad de Granada 